\title{
Impact analysis of bucket capacity and boom length of mining excavators on hoisting mechanism life
}

\author{
Sergey Kuvshinkin, Polina Ivanova
}

Saint-Petersburg Mining University, 21 Line, St. Petersburg, 199106, Russia

\begin{abstract}
The presented article considers the influence of the design parameters of the work equipment being the boom length and bucket capacity on the operating life of the hoisting mechanism of a mining excavator. The expediency of using replaceable working equipment at mining enterprises operating quarry excavators with an unchanged basic model of the machine is justified. A significant influence of the boom length, the handle length, and the bucket capacity of a quarry excavator are noted not only on the power, energy, and operational performance of the machine but also on the static and dynamic components of the load and the resource of the main drives. It has been established that an increase in the boom length does not lead to a decrease in the operating life of the hoisting mechanism. Moreover, the predominance of high-frequency components in the external load spectrum can lead to its increase. Increasing the bucket capacity at the maximum filling factor leads to the decrease in operating life.
\end{abstract}

\section{Introduction}

Currently, the main type of technological equipment used for mining operations in the open-pit mining of minerals in the Russian Federation is single-bucket quarry excavators-mechanical and hydraulic shovels. It has high specific digging forces, a reliable design, a wide range of changes in operating parameters, and most adapted to difficult quarry conditions. Different mining conditions and production capacities of mining enterprises require the use of different sizes and modifications of quarry excavators.

Note, for example, that 1406 single-bucket excavators were already in operation in the open-pit coal mining of the Russian Federation in 2006. 931 singlebucket excavators were used in the main technological processes, including 239 (25\%) for mining, 621 (67\%) for stripping, $71(8 \%)$ for dumps; the remaining 475 machines (33\%) used for odd work, were on conservation and in reserve.

Both domestic machines manufactured by "P. G. Korobkov IZ-KARTEX LLC" and "PJSC MK Uralmash", and imported excavators from "Bucyrus International Inc" and "P\&H Mining Equipment" are represented on the Russian market. The operating parameters of these machines are comparable, but the cost of imported equipment is about twice as high as domestic.

The technical characteristics of the quarry excavators currently presented on the Russian market vary widely: the bucket capacity is from $2 \mathrm{~m}^{3}$ to $64 \mathrm{~m}^{3}$, the power of the main power plant is from $240 \mathrm{~kW}$ to $4000 \mathrm{~kW}$, the weight with a counterweight is from $70 \mathrm{t}$ to $1100 \mathrm{t}$.

Mining and technical operating conditions of quarry excavators can differ significantly even within the same enterprise. It implies the use of machines with different operating parameters, in particular, having different sizes of working equipment that correspond, first of all, to the required digging height.

It is irrational to have a fleet of quarry excavators at a mining enterprise, represented by their various types, from the point of view of organizing maintenance and repair. The presence of a large fleet of similar machines, on the contrary, creates conditions for the use of more progressive and efficient systems of organization and methods of maintenance and repair, in particular, the impersonal and aggregate-node repair method, as well as the method of specialized teams.

In this regard, it seems promising to use at one enterprise, if possible, excavators of the same type with replaceable working equipment adapted for working in different faces.

The main parameters of the working equipment of a single-bucket quarry excavator are the bucket capacity, the length of the boom, and the length of the handle, and the last two parameters are rigidly interconnected.

The research conducted by the authors shows that the parameters of the working equipment of a quarry excavator have a significant impact on the power, energy, and operational performance of the machine lifting and pressure forces, power consumption of the main drives, power consumption for excavation, excavation cycle time, operational productivity, specific energy consumption.

\footnotetext{
*Corresponding author: minermech@mail.ru
} 
Changing the length of the boom, handle, and the capacity of the bucket of a quarry excavator with the base machine unchanged inevitably entails a change in the intensity of resource consumption. This is due to the influence of the parameters of the working equipment of the quarry excavator on both the static and dynamic components of the load. The influence of the parameters of the working equipment on the static component of the load is, first of all, a consequence of the change in the mass of the equipment when the length of the boom, handle, and bucket capacity change. The influence of the parameters of the working equipment of a quarry excavator on the dynamic component of the load is also explained by the change in mass, and, in addition, by the change in the rigidity of the system, which strongly depends on the length of the stele and the handle.

Abundance of unplanned mining excavators outage leads to substantial material costs both due to a decrease in minerals extraction, and high cost of repairing large assemblies and metal structures. Despite a relatively low outage caused by failures and accidents in their total number (up to $20 \%$ ), the absolute values of material losses are more significant than those caused by other reasons $[1,2,3,4]$.

Analysis of the share of mechanical and electrical subsystems of excavators in the total number of failures shows that in most cases failures of mechanical equipment prevail and account for $50-70 \%$ of their total number [5].

According to the data in the reporting and operational documentation of the limestone mine OOO "Pikalevskij glinozemnyj zavod", the mean time between failures of the gearbox of the hoisting mechanism of a mining excavator is 660 hours, and according to the "Razrez "Borodinskij" imeni M.I. SHCHadova" being a subsidiary of AO "SUEK-Krasnoyarsk" - 400 hours. In this case, most commonly the bearings of the high-speed shaft limit the gearbox operating life. The lip seals of the input shaft wear out quickly, which leads to significant oil leaks. It has to be topped up often and the level has to be kept above normal. The reliability of the output shaft splines also leaves much to be desired $[6,7,8]$.

This work uses the hoisting mechanism being the most energy-loaded one (the total power of the hoisting drive motors is comparable to the power of all other excavator drives in total) to assess the influence of the design parameters of the working equipment of an excavator on its operating life. The possibility of an isolated analysis covering the hoisting and pressure mechanisms was substantiated by the experimental and theoretical studies of Yu.A. Devyatkin and E. Ya. Timoshpolsky. It is known that the range of possible values of the design parameters characterising the working equipment of a mining excavator is almost always limited by the capabilities of the hoist drive. [8, 9]

To determine the load on the low-speed gearbox shaft of the hoisting mechanism - "output" of the dynamic system with a known load on the bucket "input", a dynamic model of the hoisting mechanism was created. It is discussed in detail in [2]. The results of modeling dynamic processes in the hoisting mechanism of the mining excavator EKG-8I with varying bucket capacity and boom length provide the basis for assessing the impact of working equipment parameters on the operating life of the hoisting mechanism.

\section{Conceptual issues of the developed methodology}

Based on the energy approach, it is possible to determine the tendencies of changes in a machine's life when varying the design parameters of working equipment. This enables to identify those directions of change in the boom length and bucket capacity that will not lead to a decrease in the excavator's operating life, and to recommend such sets of working equipment as rational if their use leads to a decrease in the total specific energy consumption for excavation and transportation under the given mining conditions [10].

The energy method for determining the resource of machines is based on the axiom that states that the gradual destruction of machine parts is determined only by the energy dissipated in these parts during operation, which does not contradict the law of conservation of energy. The energy dissipated in the machine parts determines both wear and the accumulation of fatigue damage to the parts. The basic concept of the energy method is an energy resource, i.e. the amount of energy that can be dissipated in the part before it reaches the limit state.

The energy resource can be defined as follows:

$$
\mathrm{K}_{\mathrm{K}}=\int_{0}^{\mathrm{T}_{\mathrm{p}}} \Delta \mathrm{P}(\mathrm{t}) \mathrm{dt}, \mathrm{J},
$$

where $\mathrm{Tp}$ - resource, expressed in units of time,

$\Delta \mathrm{P}(\mathrm{t})$ - power loss as a function of time.

In a deterministic form, the residual resource of the part can be determined as follows:

$$
\mathrm{T}_{\mathrm{p}}=\frac{\mathrm{K}_{\mathrm{K}}}{\Delta \mathrm{P}} \text {, hour, }
$$

where $\Delta \mathrm{P}$ - power loss.

To determine the remaining life of machine parts and components, it is necessary to continuously monitor power losses in these parts and nodes during operation, i.e. to measure the power at the input and output of the system under consideration. It is possible to carry out such control with the help of standard control and measuring devices. So, for a mechanical system (gearbox) the torque and angular velocity should be controlled, for a hydraulic or pneumatic system - the pressure and flow rate, for an electric system- the voltage, and current strength.

For mass-produced machine parts, the energy resource is a constant value that does not depend on the magnitude and nature of the external load, if the load value does not exceed the permissible values determined by the strength criterion. The absence of dependence of the energy resource on the nature of the external load allows us to use the energy method of determining the resource for mining machines and, in particular, for 
quarry excavators, the load of which is dynamic, and random, non-stationary, and non-ergodic.

The concept of "energy resource" is valid not only for individual parts but also for components and the whole machine.

It should be noted, that the use of the energy method is most convenient for determining the resource of components and aggregates, and not for individual parts since the above-described instrument control of power losses cannot be carried out for each part separately.Information about losses in the system is the basis used for considering the tendencies of changes in the system operating life. At the same time, since the drive of the hoisting winch remains unchanged when the parameters of the working equipment are varied, the value of its energy is also unchanged. In turn, the system operating life will be equal to the ratio of the system's energy to the losses amount of power dissipated in it while an excavator operates. Thus, the change in transmission resource will be proportional to the corresponding change in power loss.

To assess the magnitude of losses in the transmission based on the well-known principles considered in $[10,6$, 1], a mathematical model aimed to determine the magnitude of power losses both in the transmission as a whole and element by element depending on the magnitude and nature of the external load was developed.

Similarly, the load at the entrance to the mechanical transmission system of the hoist winch is presented as the sum of the constant and variable components. In the simulation, it is assumed that the amplitude of the variable component is $40 \%$ of the constant component value at an external load application frequency equal to $0.8 \mathrm{~Hz}$ and a frequency of $4.8 \mathrm{~Hz}$. The choice of the amplitude and frequencies is based on the research of B.P. Bagin and V.I. Olenich [11]. To identify the influence of individual parameters of the working equipment, only one of the system parameters (either the boom length or the bucket capacity) was changed each time. As shown in $[10,6,1]$, a change in the design parameters of the working equipment will entail a change in the natural frequency of the system. Consequently, this will affect the transformation of the external load when it is transferred from the excavator's actuating element to the winch drum. The simulation results enabled to graph the dependence of losses in the gearbox on the variable parameters of the working equipment with regards to the frequency of an external load application (Figure 1).

It can be seen from the graphs that the length of the boom has little effect on the losses in the hoisting winch gear due to the action of the low-frequency component of the external load, while the losses caused by the operation of the high-frequency component sharply decrease with the increase in the boom length. Consequently, an increase in the length of the working equipment with a constant bucket capacity will entail an increase in the system operating life. The dependence of the power losses on the boom length at the pre-resonant frequency of the external load application $(0.8 \mathrm{~Hz})$ is linear, and at the resonant frequency $(4.8 \mathrm{~Hz})$ it can be represented as a third-degree polynomial.
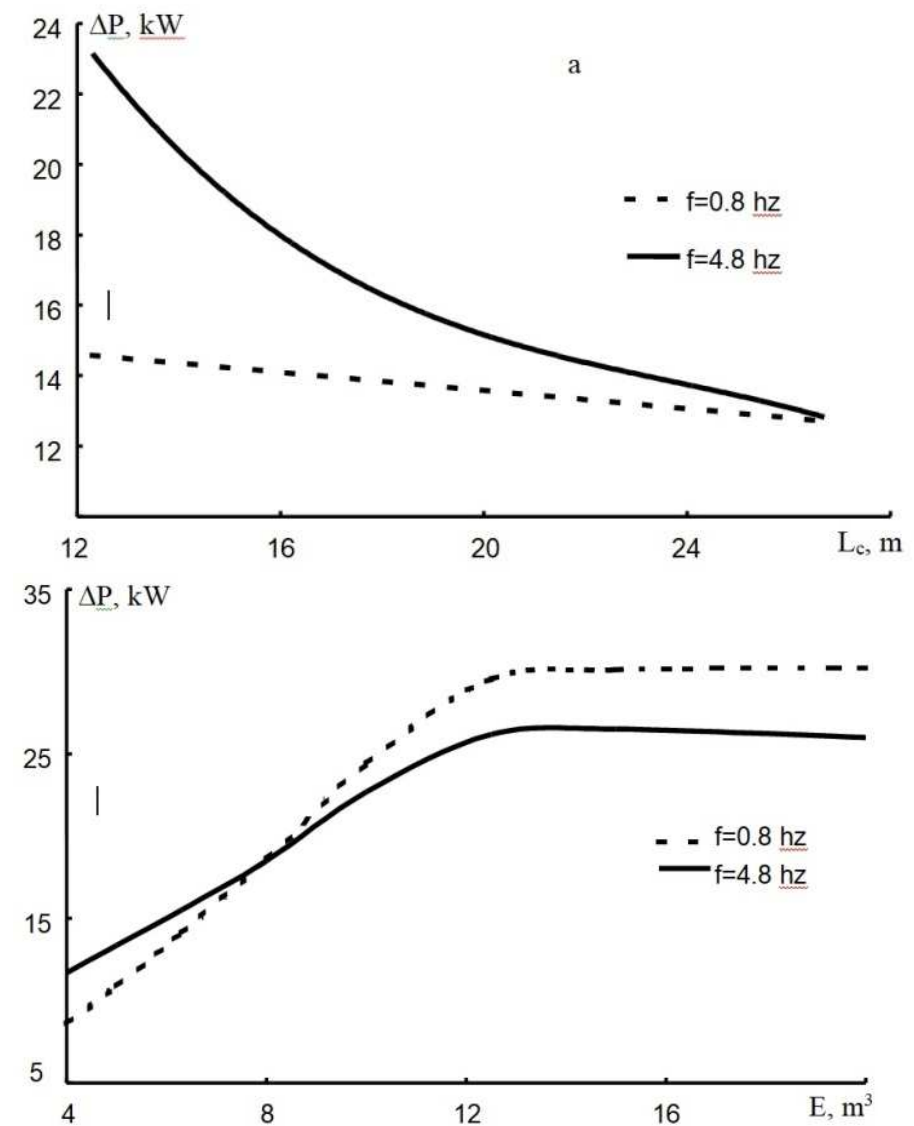

Figure 1. Power loss in the hoist gearbox depending on: a - boom length, $\mathrm{b}$ - bucket capacity 
With an increase in the bucket capacity, the losses regardless of the load frequency characteristic increase with a change in the bucket capacity from $4 \mathrm{~m}^{3}$ to 12.5 $\mathrm{m}^{3}$ according to a law being close to the linear one, and they practically do not change with a further increase in the bucket capacity. This can be explained by the fact that with a limited bottomhole height, a bucket with a capacity of more than $12.5 \mathrm{~m}^{3}$ is not completely filled. An increase in bucket capacity leads initially to an increase in losses in the hoist gearbox system, which in turn indicates a decrease in the system operating life. In this case, the nature of the change in losses regardless of the frequency of the load variable component has the same tendencies, namely: the maximum value of power losses in the system is achieved at a certain critical value of the bucket capacity, its further increase does not lead to an increase in losses, and, consequently, to a further decrease in system operating life. The characteristic critical zone is due to the fact that when it is reached, the filling factor of the ladle decreases. The location of such a zone is determined primarily by the bottomhole height.

In conclusion, it should be stated that the design parameters of the working equipment of a mining excavator have a significant impact on the amount of power loss in the mechanical system, and, consequently, on its operating life. At the same time, an increase in the boom length does not influence the capability, and in the case of a predominance of the high- frequency part of the spectrum of the load variable component, it can even lead to its increase. The choice of the bucket capacity should be approached with greater caution since an increase in its capacity with a constant value of the filling factor will obviously reduce the system operating life, and the use of a bucket, whose maximum filling is impossible under the given conditions, does not make sense.

\section{Conclusion}

1. The expediency of using replaceable working equipment of quarry excavators with an unchanged basic model of the machine is justified.

2. The influence of the main parameters of the working equipment of a quarry excavator - the length of the boom, handle, and bucket capacity on the power, energy, and operational performance of the machine are established.

3. The influence of the boom length, the handle length, and the bucket capacity of the quarry excavator on the static and dynamic components of the load of the main drives are noted.

4. The influence of the length of the boom, the length of the handle, and the bucket capacity of the quarry excavator on the resource of the main drives are noted.

5. The possibility of using the energy method for determining the resource for mining machines, in particular, for quarry excavators, is justified.5. A dynamic model of a mining excavator hoisting mechanism has been developed. The model enables to determine the magnitude and nature of the load on the low-speed shaft of the gearbox at a known load on the bucket.

6. A mathematical model for the hoisting mechanism of a mining excavator enabling to determine the values of power losses both in the transmission as a whole and element-by-element depending on the magnitude and nature of the external load has been developed.

7. It has been established that the change in the transmission resource will be proportional to the corresponding change in the power losses in it.

8. It has been established that an increase in the lengths of the boom and handle does not lead to a decrease in the lifespan of the lifting mechanism, and in the case of a predominance of the high-frequency component in the load spectrum, it can even lead to its increase, while an increase in the bucket capacity with a constant filling factor entails a decrease in capacity.

\section{References}

1. S.L. Ivanov Journal of Mining Institute, 221, 692$700 \quad$ (2016). DOI: http://dx.doi.org/10.18454/spmi.2016.5.692.

2. S.Yu. Kuvshinkin Innovations and Prospects for the Development of Mining Engineering and Electromechanics: IPDME 2018. (SPb: SaintPetersburg Mining University, 2018).

3. A.V. Mikhailov, A.I. Zhigulskaya, T.B. Yakonovskaya, IOP Conference Series: Earth and Environmental Science, 87(2), 022014, (2017). DOI: $10.1088 / 1755-1315 / 87 / 2 / 022014$

4. N.V. Dyorina, V.S. Velikanov, K.S. Dyorina IOP Conference Series: Materials science and engineering, 971, 042026, (2020). DOI: 10.1088/1757-899X/971/4/042062

5. V. Velikanov, N. Dyorina, O. Panfilova MATEC Web of Conferences, 224, 02010, (2018) DOI: 10.1051/matecconf/201822402013

6. V.S. Velikanov, O.R. Panfilova, I. G. Usov Bulletin of the Moscow State Technical University named after G.I. Nosov. 16 (4), 13-20, (2018) DOI: https://doi.org/10.18503/1995-2732-201816-3-13-20.

7. S.L. Ivanov Journal of Mining Institute, 221, 692700 (2016).

8. S.U. Kuvshinkin, P.V. Ivanova IOP Conference Series: Earth and Environmental Science. 378, 012121, (2019) DOI: 10.1088/1755$1315 / 378 / 1 / 012121$

9. O.P. Panfilova, V.S. Velikanov, I.G. Usov, E.Y. Matsko, I.M. Kutlubaev Journal of Mining Science, 54(2), 218-225, (2018) DOI: $10.1134 / \mathrm{S} 1062739118023570$

10. M.D. Kolomiytsev, B.S. Makhovikov Notes of SPGGI, 138, 84-94, (1993).

11. B.P. Bagin, V.I. Olenich Fundamentals of the statistical dynamics of single-bucket excavators, (Moscow: TsNIITEstroymash, 1974) 